\title{
Marketing Benefits Derived from Clustering: the Case of Vegetable Clusters in Mindanao
}

\author{
R.J.G. Lamban, M.O. Montiflor, R.R. Rodel, J.T. Axalan and S.B. Concepcion \\ School of Management \\ University of the Philippines Mindanao \\ The Philippines
}

R.H. Bacus, D.I. Apara and F.T. Israel

UP Strategic Research and Management Foundation Incorporated

University of the Philippines Mindanao

The Philippines

\author{
P.J. Batt, R.B. Murray-Prior and M.F. Rola-Rubzen \\ Curtin University \\ Perth \\ Western Australia
}

Keywords: collaborative marketing, market access, quality, packaging, transportation

\begin{abstract}
One of the most limiting constraints for improving the profitability of smallholder vegetable farmers is poor marketing. With the lack of knowledge and inability to negotiate with downstream buyers, farmers have little option other than to sell their products to the traditional market. To facilitate access to technical information, credit and institutional markets, smallholder farmers are forming collaborative marketing groups. Clustering is one form of collaborative marketing in which smallholder farmers are organized into small groups within a defined territory or geographic area. Using the CRS Eight Step Plan for Agro-enterprise Development, 29 clusters were formed in three provinces in the Southern Philippines. This study explores the various marketing benefits smallholder farmers have achieved after joining the cluster. After interviewing 61 vegetable farmers from 10 clusters using a structured questionnaire, results show that upon joining the cluster, farmers became more aware of their buyer's preference for product quality and gained knowledge on how to properly handle and package their produce. Cluster farmers increased their income from vegetable farming by selling a greater product variety, a larger volume and gaining access to high value markets.
\end{abstract}

\section{INTRODUCTION}

One of the most limiting constraints for improving the profitability of smallholder farmers is marketing (Montiflor et al., 2011). Moreover, improving agricultural marketing has been a continuous undertaking in the Asian region, where farmers have been burdened with limited resources, changing consumer demands and inefficient supply chains (Manalili, 2003). With the lack of knowledge and inability to negotiate with buyers, farmers have little option other than to sell their products through the traditional markets. Acting independently, smallholder vegetable farmers find it difficult to meet the quality and quantity demands of institutional buyers because they lack financial capital 
and their small farm size (Montiflor et al., 2011). External factors such as poor transport infrastructure, high transport and handling costs, limited access to physical inputs, credit and information, high transaction costs and the lack of government and institutional support all contribute to the difficulties smallholder farmers experience in entering highvalue markets (Murray-Prior, 2007).

The agricultural research and development community has started to recognize the need for smallholder producers to move away from a traditional focus on production towards a more market orientated strategy to improve on-farm income (APAARI, 2008). This approach requires linkages to be established between input suppliers, producers and market intermediaries. An outstanding example of this approach is the Eight Step Clustering Approach for Agro-enterprise Development developed by the Catholic Relief Services.

Under the clustering approach, farmers are organized into small groups called clusters (CRS, 2007). This approach employs a process of eight steps. The first five steps emphasize the need for farmers to learn new skills, access new information, and adopt innovative methods to be able to identify and respond to market demands and opportunities. Adequate preparation during this first phase ensures a higher degree of success when actual marketing takes place in Step 6 (test marketing). After this, the cluster is asked to reflect and to decide if they want to continue with their agro-enterprise development plan. At this point in time, the farmers formally come together into clusters and develop links with the institutional market.

The clustering approach focuses not only on improving smallholder farmer's production system, but also on how their products can more efficiently reach the market. This is achieved through collaborative marketing where the farmers come together to collectively sell their produce to a preferred buyer. This collaborative action aims to lower farmers' transaction costs, gain better access to markets, better bargaining power, and improve the income of smallholder vegetable farmers.

The key benefits of clustering can be economic, environmental and social (Lamban et al., 2010). Economic benefits include higher prices for products, lower costs, higher income, improved market access, improved access to technical information and capacity building, greater access to production inputs and greater access to working capital. The adoption of natural farming technologies and contour farming has had a positive impact on the environment. The capacity to negotiate with buyers and to establish market linkages has enabled the clusters to diversify their markets and their product range, to provide additional employment for the community, to improve social connections and access to information and infrastructure. Perhaps the most significant and long-term social benefit has been the ability of cluster farmers to send their children to school.

Through clustering, farmers have a better understanding of the market dynamics, price fluctuations and the product specifications they must meet to satisfy their downstream buyers' needs (Lamban et al., 2010). A better understanding of the market enables farmers to overcome much of the distrust and apprehension that has been present in the traditional market. Moreover, cluster members feel more empowered with the skills and information acquired through training, workshops and seminars. They now have the capacity to make their own decisions, especially in dealing with buyers and in developing alternative markets for existing and new products. This paper will highlight some of the on-farm benefits farmers have gained from participating in the clustering process. 


\section{SITE DESCRIPTION}

Mindanao, the second largest island in the Philippines, is composed of six regions, 26 provinces and is home to over 21.6 million residents. In this study, research was undertaken in three provinces: Bukidnon, Davao City and South Cotabato.

Bukidnon has 22 municipalities and a total land area of 1.05 million ha. Two clusters were situated in the municipality of Lantapan, one in Impasugong, and four in Malaybalay City. Lantapan lies at an altitude of $1,130 \mathrm{~m}$ above sea level and has a total population of 51,406. The municipality is composed of 14 barangays, including Songco and Kaatoan. The Songco and Kaatoan clusters were each composed of 13 farmers. Impasugong is the largest of the 22 municipalities in Bukidnon. The cluster in Impasugong is composed of six farmers who primarily plant bitter gourd. Malaybalay, the capital city of Bukidnon, is composed of 46 barangays. The Kilapagan Gardeners Association is composed of two clusters located in Purok 6 and 7 of Barangay Can-ayan. Both clusters have 13 members.

Davao City is one of the largest cities in the world. It is composed of 184 barangays, including Barangay Saloy and Barangay Marilog, both of which are located some $50 \mathrm{~km}$ from the CBD. The members of the Saloy Small Vegetable Farmers Association (SASVEFA) reside in this barangay. Four clusters are situated in Barangay Marilog.

Barangay Ned is part of the municipality of Lake Sebu in South Cotabato. It has a land area of approximately 41,247 ha, divided into 32 sitios with a population of 15,378. Two clusters were located in Barangay Ned.

All of the clusters grow one or more temperate and semi-temperate vegetable crops for the traditional and emerging institutional markets. These include food processors and manufacturers, the food service industry and modern retailers.

\section{METHODOLOGY}

Information for this study was collected from key informant interviews, baseline and final cluster surveys, and project reports. Since 2008, 29 clusters were formed using the CRS clustering approach. These clusters were formed with the aim of organizing them to collaboratively market their produce and to link them with the market. Of the 29 clusters, 10 were chosen to be interviewed. Members were interviewed upon joining the clusters and again in 2011. A total of 61 vegetable farmers were interviewed using a structured questionnaire. They were asked about their farming practices, product utilization, production and marketing costs, labour utilization, cluster satisfaction and impacts of clustering. Data was compared to see if farmers had benefited from clustering.

\section{RESULTS AND DISCUSSION Better market access}

According to Narrod et al. (2007)(cited by Zoss and Pletziger, 2007), for smallholder farmers to overcome constraints like the small quantity of produce available, the heterogeneous quality of the produce and limited access to input supplies, capital, market information and the necessary farm management skills, it is necessary for farmers to come together collectively. To enable smallholder farmers to respond to the challenges presented by modern institutional markets, smallholder farmers have begun to collectively market their produce. Through consolidation, farmers are able to aggregate a sufficient supply of good quality produce to meet their buyer's needs, to reduce transaction costs and to improve their bargaining power. 
From the experience of vegetable farmers in the Southern Philippines, clustering has enabled smallholder farmers to access institutional markets. To facilitate price setting, experience has taught the clusters to regularly monitor prices in the traditional market to provide a base price for their negotiations. With access to higher value markets, farmers have been able to receive higher prices for their products (Figure 1). In one instance, there was an observed price difference of $33 \%$ to $85 \%$ between the traditional and institutional market price. This difference can be attributed to the improved quality of the produce sold in the institutional market.

\section{Product variety}

Sweet pepper was the most commonly planted crop by farmers in South Cotabato and Bukidnon. Clusters from both areas chose sweet pepper as their primary product during the product selection stage of the clustering process. The product was chosen by the clusters because they had contacted a market facilitator whose buyer wished to buy sweet pepper. However, after several clusters experienced crop failure due to erratic weather conditions and pest and disease infestation, farmers planted additional products such as bulb onion, bitter gourd and squash to spread the risk. For the clusters in Davao, farmers used to plant one or two products on their small parcels of land. When farmers were faced with bad weather conditions, they decided to plant a greater range of vegetable crops. Fortuitously, their buyers were also looking for a greater variety.

\section{Grading and sorting}

Vegetable farmers in all three areas used to sell kuridas (all inclusive) to their buyers. This means that farmers received the same price for all their produce, irrespective of quality. This situation arose because they did not know that they could obtain different prices for better quality produce, for larger product or product which was more mature (red pepper vs green pepper). After clustering, farmers learned how to sort their products according to their buyer's specification and as a result they received different prices for different quality produce.

\section{Packaging and postharvest handling}

Farmers are conservative when it comes to packaging their produce. They use sacks to pack vegetables such as sweet pepper, chayote, Baguio beans, squash and Malabar spinach, and sometimes they use second-hand cartons to pack bitter gourd. Pechay and other leafy vegetables are packed using a bukag (rattan basket) and tomatoes are packed in wooden crates. To reduce the cost of transport, farmers generally over pack sacrificing the quality of the produce. This practice causes damage and bruising which reduces the appearance of the produce. In one of the training programs conducted for the farmers, they began to understand the importance of appropriate product packaging, especially for highly perishable products. After the training, the cluster farmers requested assistance in purchasing plastic crates that could be used in packing and transporting their produce to their respective buyers. Today, most of the clusters place their produce in plastic crates to deliver it to their buyers, except for squash and pechay.

Another improvement brought about by clustering is the consciousness of farmers in handling their produce properly. According to Pennsylvania State University (2000), postharvest handling is one of the critical processes in marketing. Aside from over packing their produce, farmers would quite literally throw their produce around before packing it. During transport from the farm to their buyer, the produce was often placed on 
top of the jeepney, where some passengers would sit on top of the vegetables. After joining the cluster, farmers became more aware of the damage caused by the improper handling of vegetables. With better communication with their buyers, farmers are now aware that damaged vegetables were one of the reasons for the low prices they received. Having a high value market like a supermarket, the farmers are more careful in handling their produce. Any product that fails to pass the quality inspection of the supermarket will be returned to the cluster. Proper handling and packaging of vegetables has reduced the postharvest loss by $2 \%$.

Another aspect most farmers disregard during marketing is the cleanliness of their produce. After harvest farmers immediately pack their produce and deliver it to their buyer. Farmers failed to recognize the importance of delivering washed and clean produce to their buyer. When farmers had the chance to talk to potential buyers, they found that buyers like some vegetables to be washed and cleaned before delivery. Farmers learned that it was to their advantage to wash their vegetables before delivery. Not only did this remove dirt and other foreign matter, but it improved the physical appearance of the produce.

\section{CONCLUSION}

Marketing is important for all farm enterprises. Clustering has proved to be very effective as a tool to help smallholder vegetable farmers in the Southern Philippines to improve their livelihood. Through consolidation, farmers have been able to access both traditional and institutional markets, to maintain a consistent supply of good quality product to their chosen buyer, and negotiate a fair price for their products. Through training and capacity building activities, smallholder farmers are more empowered and more capable of making better decisions, which both directly and indirectly impact on their livelihoods. Moreover, becoming aware of what the market wants, farmers can respond efficiently enabling them to maximize their profit.

\section{ACKNOWLEDGEMENT}

Financial support from the Australian Centre for International Agricultural Research (ACIAR) and the use of the Eight Step Plan for Agro-enterprise Development developed by the Catholic Relief Services (CRS) is duly acknowledged.

\section{Literature Cited}

Asia-Pacific Association of Agricultural Research Institutions. 2008. Linking farmers to market: some success stories from Asia-Pacific region. Bangkok, Thailand.

Catholic Relief Services. 2007. The clustering approach to agroenterprise development for small farmers: The CRS-Philippines experience - a guidebook for facilitators. Catholic Relief Services - USCCB Philippine Program.

Lamban, R.J.G., Montiflor, M.O., Real, R.R., Axalan, J.T., Concepcion, S.B., Bacus, R.H., Apara, D.I., Israel, F.T., Batt, P.J., Murray-Prior, R.B. and Rola-Rubzen, M.F. 2010. Benefits of collaborative marketing groups: case of clustering in Mindanao. Proceedings of the Mindanao Conference on Issues in Development, Davao City, Philippines, November.

Manalili, N. M. 2003. Linking farmers to markets through cooperatives vegetables supply chain redesign options for Kapatagan, Davao del Sur. Proceedings of the Australian Agricultural and Resource Economics Society Conference. February. 
Montiflor, M.O., dela Cerna, A.K.R., Lamban, R.J.G., Bacus, R.H., Concepcion, S.B., Batt, P.J. and Murray-Prior, R. 2011. Social connections and smallholder vegetable farmers' collaborative marketing strategy: the case of small farmers association of Quirogpang in Davao City, Philippines. Acta Horticulturae 895: 177-184.

Murray-Prior, R.B. 2007. The role of grower collaborative marketing groups in developing countries. Stewart Postharvest Review: 6:15.

Pennsylvania State University. 2000. Fruit and vegetable marketing for small-scale and part-time growers. Agricultural Alternatives.

Zoss, M. and Pletziger, S. 2007. Linking African vegetable smallholders to high value markets: potentials and constraints in smallholders' integration into GLOBALGAPcertified and/or domestic African high value supply chains. Presented at the Conference on International Agricultural Research for Development, October 9-11.

Figure 1: Average monthly price comparison, January 2011 to March 2012

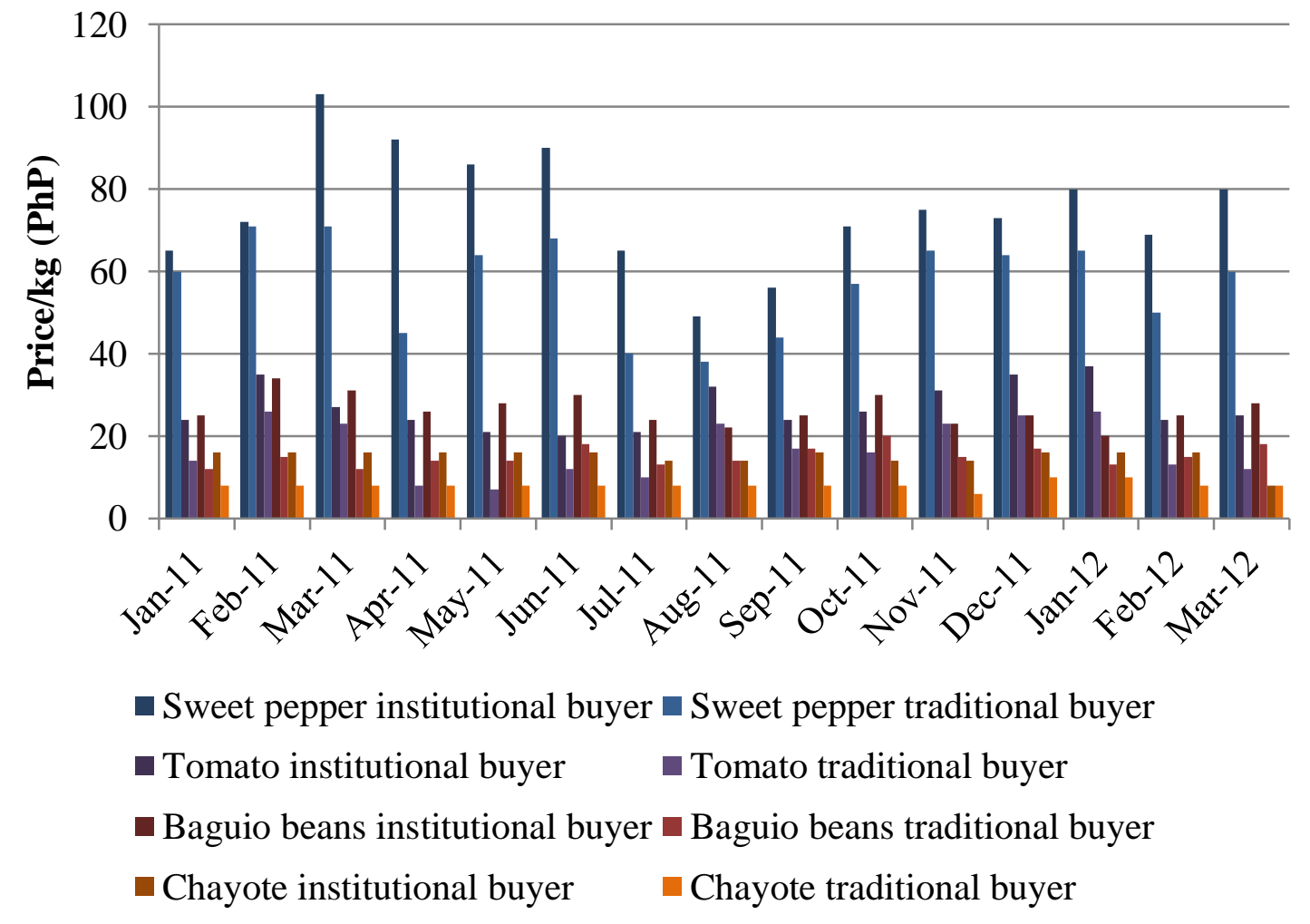

